\section{Commentary: Thoracic surgery milestones as an iterative process: Try and try again}

\author{
Mara B. Antonoff, MD
}

The Thoracic Surgery Milestones ${ }^{1,2}$ have represented a key component of the current process for evaluating residents in our specialty for over 5 years, yet details of their development have remained somewhat elusive to many practicing surgeons. Mitzman and colleagues ${ }^{3}$ should be commended for providing clarity to the purpose, process, and construct of the Milestones through their contribution to the Journal. Moreover, these authors and their colleagues on the Thoracic Surgery Milestone 2.0 Working Group should be further applauded for their enormous efforts to take on this iterative process. As outlined by Mitzman, Milestones 2.0 will be a streamlined, simplified improvement to the inaugural version, including harmonization of the more general competencies across all specialties. ${ }^{3}$

Why the need for revisions and harmonization? At a broad level, there were widely ranging strategies described across specialties for reporting on Professionalism, Practice-Based Learning, Interpersonal and Communication Skills, and Systems-Based Practice. ${ }^{3,4}$ Moreover, at local and anecdotal levels, surgeon educators have, at times, expressed skepticism regarding the utility of the tools and validity of the rating scales. Why were there so many inconsistencies among specialties, and why couldn't the creators of the Milestones nail the perfect assessent tools the first time? Why the need for an iterative process?

Ultimately, one must recognize that the science of surgical education, in many ways, is different than that of clinical cardiothoracic surgery. We are accustomed to a world of established risk prediction models, such as the Society of

\footnotetext{
From the Department of Thoracic and Cardiovascular Surgery, University of Texas MD Anderson Cancer Center, Houston, Tex.

Disclosures: Author has nothing to disclose with regard to commercial support.

Received for publication Dec 16, 2019; revisions received Dec 16, 2019; accepted for publication Dec 16, 2019; available ahead of print Jan 7, 2020.

Address for reprints: Mara B. Antonoff, MD, Department of Thoracic and Cardiovascular Surgery, University of Texas MD Anderson Cancer Center, 1515 Holcombe Blvd, Houston, TX 77030 (E-mail: MBAntonoff@mdanderson.org).

J Thorac Cardiovasc Surg 2020;160:1405-6

$0022-5223 / \$ 36.00$

Copyright (c) 2020 by The American Association for Thoracic Surgery https://doi.org/10.1016/j.jtcvs.2019.12.062
}

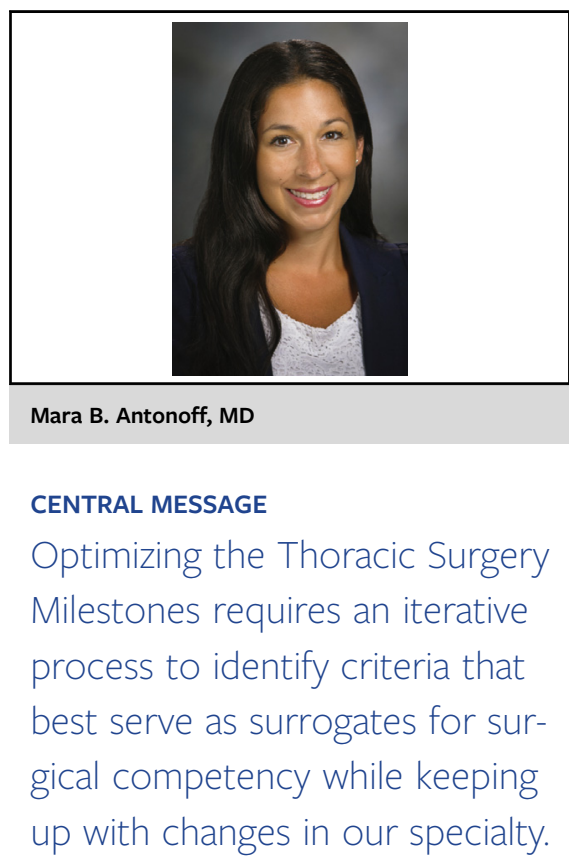

Thoracic Surgeons Cardiac Risk Score and the European System for Cardiac Operative Risk Evaluation II. ${ }^{5}$ We are used to employing risk models to determine likelihood of renal failure after valve replacement or using pulmonary function tests to stratify patients at risk for death after pneumonectomy. ${ }^{6}$ Why is it simpler to develop an algorithm to predict complications after a major operation than to predict likelihood of success as a trainee? For starters, what exactly does "success as a trainee" look like? Certainly, it is an outcome that may be hard to define. Measuring predicted postoperative pulmonary function or calculating degree of renal impairment by RIFLE criteria may be done by implementing mathematical formulae and clear criteria. ${ }^{7}$ In the realm of surgical education, we must concern oursleves with issues of validity and other relevant metrics ${ }^{8,9}$ - but what are we measuring? What exactly is our outocme of interest? Whether it be inservice scores, board-passage rates, or some other outcome, we are still, in the end, using an assessment tool as a marker or surrogate for something bigger and much less concrete-whether a trainee knows enough, has the appropriate skills, and represents a "good cardiothoracic surgeon." This is a far less easily defined outcome than oxygen dependence or mortality, which tend to be discrete, measurable, and less subjective. Thus, in many ways, the Milestones Working Group has taken on a gargantuan task-not only to optimize the assessment tool, but also to choose exactly which proxies for "good surgeon" are worthy of evaluation. Moreover, as our field 
evolves in terms of technology and treatment practices, Milestones will need to transform in parallel, to ensure that trainees learn up-to-date procedures and skillsets.

For all of these reasons, the Milestones Project will continue to be an iterative process, and feedback from practitioners and educators is vital to its improvement. As highlighted by Mitzman and colleagues, there are a number of tasks that must be undertaken by individual programs after implementation of the new Milestones: review of the assessment tools in place, meeting of the clinical competency committee, faculty asseessment, and resident self-assesment. ${ }^{3}$ However, beyond these expectations, it will be incredibly important for faculty and residents to provide ongoing feeback on the Milestones, to ensure both their relevance and efficacy in assessing trainees in our specialty. In the interim, as we reflect on what makes a "good surgeon," we look forward to the reveal of the Milestones 2.0, and we must recognize and accept the need for this to be an iterative process to achieve continued growth.

\section{References}

1. The Thoracic Surgery Milestone Project. J Grad Med Educ. 2014;6(1 suppl 1): 332-54.

2. Yang SC, Merrill W. Educational milestone development in phase II specialties: thoracic surgery. J Grad Med Educ. 2014;6(1 suppl 1):329-31.

3. Mitzman B, Beller J, Edgar L. Thoracic Surgery Milestones 2.0: Rationale and Revision. J Thorac Cardiovasc Surg. 2020;160:1399-404.

4. Edgar L, Roberts S, Yaghmour NA, Leep Hunderfund A, Hamstra SJ, Conforti L, et al. Competency crosswalk: a multispecialty review of the Accreditation Council for Graduate Medical Education Milestones across four competency domains. Acad Med. 2018;93:1035-41.

5. Sullivan PG, Wallach JD, Ioannidis JP. Meta-analysis comparing established risk prediction models (EuroSCORE II, STS score, and ACEF score) for perioperative mortality during cardiac surgery. Am J Cardiol. 2016;118:1574-82.

6. Safi S, Benner A, Walloschek J, Renner M, op den Winkel J, Muley T, et al. Development and validation of a risk score for predicting death after pneumonectomy. PLoS One. 2015;10:e121295.

7. Bellomo R, Kellum JA, Ronco C. Defining and classifying acute renal failure: from advocacy to consensus and validation of the RIFLE criteria. Intensive Care Med. 2007;33:409-13.

8. Antonoff MB, Nguyen S, Nguyen TC, Odell DD. Conducting high-quality research in cardiothoracic surgical education: recommendations from the Thoracic Education Cooperative Group. J Thorac Cardiovasc Surg. 2019;157:820-7.e821.

9. Corsini EM, Antonoff MB. Surgical education research: How to move beyond the survey. Surgery. 2020;167:269-72.
See Article page 1399.

\section{Commentary: Bigger...badder... better?}

Anh-Thu Le, MD, and Nahush A. Mokadam, MD

It is the rare human who enjoys being scrutinized, and surgeons even less so. Many of us believe we are entirely capable of accurate self-reflection and that we can independently use that self-reflection to improve ourselves. Impossible as it may seem, there is one thing more irksome for surgeons than evaluating themselves, and that is evaluating others. Trainees and faculty collectively bemoan the pesky forms lurking in our inboxes, and the thought of filling them out incites excruciating pain. In fairness, the evaluations can seem onerous, with countless online modules, finicky phone

From the Division of Cardiac Surgery, The Ohio State University Wexner Medical Center, Columbus, Ohio.

Disclosures: Dr Mokadam is a consultant for Medtronic, Abbott, SynCardia, and Carmat. Dr Le has nothing to disclose with regard to commercial support.

Received for publication Jan 10, 2020; accepted for publication Jan 12, 2020; available ahead of print Jan 23, 2020.

Address for reprints: Nahush A. Mokadam, MD, Division of Cardiac Surgery, The Ohio State University, Columbus, OH 77030 (E-mail: Nahush.Mokadam@ osumc.edu).

J Thorac Cardiovasc Surg 2020;160:1406-7

$0022-5223 / \$ 36.00$

Copyright (c) 2020 by The American Association for Thoracic Surgery

https://doi.org/10.1016/j.jtcvs.2020.01.011
Check for updates

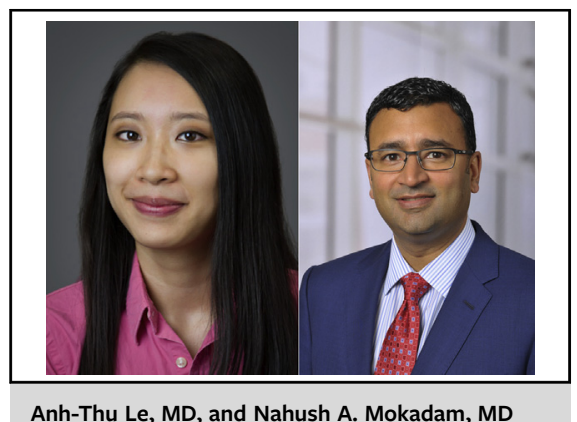

Anh-Thu Le, MD, and Nahush A. Mokadam, MD

CENTRAL MESSAGE

The revision to the ACGME

Milestones is needed and a work-

in-progress. This is essential to

ensure resident and faculty

engagement, as well as to pro-

vide beneficial feedback to

trainees and programs.

"apps," and committees to participate in fulfilling criteria laid out by the Accreditation Council for Graduate Medical Education (ACGME) guidelines. ${ }^{1-3}$ At many institutions, faculty use burdensome Web sites to fill out evaluations and score residents on the basis of the competencies. In 